\title{
Review of Seismic Structure of the Continental Lithosphere with Results from the Southern Africa Seismic Experiment
}

\author{
James, D.E. ${ }^{1}$, van der Lee, S. ${ }^{1}$, Gao, S. ${ }^{1}$, Silver, P. ${ }^{1}$, VanDecar, J. ${ }^{1}$, Kuehnel, R. ${ }^{1}$ \\ Jordan, T.H. ${ }^{2}$, Saltzer, R. ${ }^{2}$ Gaherty, J. ${ }^{2}$ \\ Goré, J. ${ }^{3}$, Zengeni, T. \\ Nguuri, T. ${ }^{4}$, Wright, C. ${ }^{4}$, Webb, S. ${ }^{4}$ \\ Burford, D. ${ }^{5}$, Doucouré, M. ${ }^{5}$, Molisana, M. ${ }^{5}$ \\ Green, R. ${ }^{6}$ \\ Robey, J. ${ }^{7}$, Harvey, J. ${ }^{7}$ \\ Kostlin, E. ${ }^{8}$ \\ Reichhardt, F. ${ }^{9}$ \\ (authorship ordered by affiliation) \\ 1. Department of 'Terrestrial Magnetism, Carnegie Institution of Washington, \\ 5241 Broad Branch Rd., NW, DC 20015 \\ 2. Massachusetts Institute of Technology, Cambridge, MA \\ 3. University of Zimbabwe, Harare, Zimbabwe \\ 4. University of the Witwatersrand, Johannesburg, South Africa \\ 5. University of Cape Town, Capetown, South Africa \\ 6. Green's Geophysics, Ladismith (West Cape), South Africa \\ 7. de Beers Geology, Kimberley, South Africa \\ 8. Anglo American Corp. Ltd., Johannesburg, South Africa \\ 9. Rio Tinto Zimbabwe, Harare, Zimbabwe
}

The continental lithosphere may be viewed as a mechanical boundary layer, a thermal boundary layer, or a chemical boundary layer. These definitions postulate fundamentally different properties by which lithosphere will be described and have very different implications for its thickness (James, 1989, for review). This ambiguity in the meaning of lithosphere led Jordan (1978) to abandon the term in favor of "tectosphere" for identifying the deep conductive layer beneath continents. For this presentation we use tectosphere in the usual way to signify the long-lived component of the subcontinental mantle that remains attached to the overlying crust through geologic time and does not participate in convective processes that produce mixing in other parts of the mantle. We will further consider that the chemical and thermal properties of the deep tectosphere are such that, at least in principle, the root stucture can be imaged seismically (e.g. Jordan, 1979, 1981).

A buoyant and geochemically distinct tectospheric mantle keel beneath some cratons is known from study of mantle xenoliths to extend to at least $200 \mathrm{~km}$ depth. Re-Os isotope model ages show, moreover, that the age of lithospheric mantle xenoliths erupted through cratons such as the Kaapvaal is similar to that of the overlying crust over the entire depth range of mantle xenoliths, indicating that the mantle keel has been thermally and chemically stable for at least $3 \mathrm{Ga}$ (e.g. Carlson et al., this conference). These Re-Os results are consistent with models for the relatively rapid formation of Archean lithospheric mantle and for its long-term stability.

Results showing a geochemically stable mantle to great depth are buttressed by a wide range of seismological studies. Early travel time studies of vertically travelling $\mathrm{ScS}$ phases and continental scale $S$ and multiple $S$ wave propagation showed that shear wave velocities are significantly higher in the upper mantle beneath shields relative to oceanic areas to depths perhaps as great as 300 to $400 \mathrm{~km}$ (e.g. Sipkin and Jordan (1980)). Subsequent continent scale tomographic studies since have largly verified the early results (e.g. Grand (1987), Zielhuis and Nolet (1994), van der Lee and Nolet (1997), providing further evidence that the tectosphere may extend well below that part of the upper mantle sampled from xenoliths. This region of the deep mantle thus appears to hold the key for 
understanding the mechanisms of formation and long-term stabilization of cratonic roots and the nature of the decoupling between those roots and the underlying convecting asthenospheric mantle. The depth zone between 200 and $400 \mathrm{~km}$ is among the most difficult to study by any seismic means at levels of resolution that are geologically meaningful. The southern Africa seismic experiment was designed specifically to provide just such high resolution imaging of the deep root zone of cratonic nuclei.

Another important seismic measure that bears directly on the dynamical formation of the cratonic mantle comes from observations of shear wave anisotropy. Mantle shear wave anisotropy can be interpreted to be a measure of the degree of olivine alignment in the mantle that has occurred as as result of tectonic stresses (see, for example, Silver and Chan, 1988).

One of the most remarkable findings of studies of anisotropy is that in some areas of ancient crust the shear wave splitting appears to measure 'fossil' anisotropy, fabric formed during the last major tectonic event(s) to affect the lithospheric mantle. In such cases, the fast direction for shear waves is presumed to be in the direction normal to the direction of maximum compressive stress of the last major tectonic cycle. If correct, this suggests that crystal orientations established in the Archean are still intact and that the cratonic lithosphere is not only thick, but highly resistant to deformation by convective instability and thermal disruption.

\section{The Southern Africa Seismic Experiment}

The Southern Africa Seismic Experiment was designed specifically to tackle the above issues of the deep structure of cratonic roots. The experiment is part of a large-scale multidisciplinary research project by Carnegie Institution, MIT, southern African academic institutions and several industry collaborators to study the structure, composition, and evolution of the Kaapvaal and Zimbabwe cratons and their relationship to adjacent mobile belts. To carry out the project, an array of fifty five portable broadband seismic stations was deployed in April/May 1997 along a NNE-SSW transect about $1800 \mathrm{~km}$ long by $600 \mathrm{~km}$ wide in southern Africa as shown in Figure 1. The array extends in a swath from the Cape Fold Belt and Namaqua-Natal mobile belt in South Africa, through the Kaapvaal craton, across the Limpopo Belt, and into the cratons of Zimbabwe and Botswana. Seismic observations will continue for a period of two years: about half the stations will be redeployed at the end of the first year, for a total observing network of about 82 stations. It is possible in addition that we will install a telemetered broadband array with aperture around $100 \mathrm{~km}$ in the vicinity of Kimberley. That array will provide very high resolution imaging capabilities for mapping the deep root structure of kimberlite pipes and very detailed discontinuity structure of the upper mantle.

The array of REFTEK/STS-2 seismograph systems is configured to image the crust and mantle beneath southern Africa at a resolution of better than $100 \mathrm{~km}$. The experiment focuses on three principal areas of study: (1) The smooth tomographic structure of the deep craton and adjacent geologic terranes; (2) The nature and depth of mantle and crustal discontinuities; and (3) The anisotropic structure of the cratonic mantle. All results at this time are extremely preliminary, but already reveal some important findings.

Tomographic Structure. Tomographic structure across the array is determined both from body wave delay times (P and $\mathrm{S}$ ) and from surface waves. Preliminary results from both surface waves and body waves clearly image the high velocity root beneath the craton to a depth of at least $200 \mathrm{~km}$ and perhaps substantially more (James et al., 1997). Very preliminary results seem also to indicate that the root itself may have significant heterogeneity, as evidenced by apparently higher velocities in the upper mantle beneath the southern part of the craton in the general region of Kimberley. We will present tomographic results for both $\mathrm{P}$-wave and $\mathrm{S}$-wave velocity structures.

Discontinuity Structure. The work of several students on depths to the crust/mantle boundary (the Moho) will be presented as well as some preliminary results on deeper discontinuities. Early results based on the receiver function method show that there may be substantial variations in crustal 
thickness across the Kaapvaal craton itself, as well as significant changes in thickness across the boundaries between craton and adjacent Proterozoic provinces.

Anisotropy Structure. Perhaps the most remarkable of the early seismic results is that transverse anisotropy in the mantle beneath the craton is either absent or very weak as measured by SKS splitting (James et al., 1997).

We have obtained SKS splitting measurements for most of the stations, although the number of observations for each station differs by up to a factor of 10 across the array. At the time of writing, we have identified 84 events with at least one clear SKS or SKKS arrival. These events cover a broad range of back azimuths (great circle azimuth, measured clockwise from north, from station to epicenter). The total number of reliable measurements to date is about 300 . A vast majority of the measurements are null, indicating either no azimuthal anisotropy or fast and slow axes parallel to the direction of wave propagation. Several stations do exhibit some anisotropy, however, with splitting times less than 1 second. Most of these stations are located at the SW corner of the Kaapvaal craton. The data here are relatively sparse, however, so the results must be considered quite preliminary.

The MIT group has used earthquakes recorded during the first few months of the array deployment to estimate the average velocity structure beneath the Kaapvaal craton (Jordan et al., 1997). Surface waves from northeasterly back-azimuths propagate across the array significantly faster than expected for a PREM-type upper mantle. Frequency-dependent travel times from the fundamental Love and Rayleigh waves, as well as a limited set of overtone-dominated waveforms, have been inverted for sub-array structure using a procedure that allows for heterogeneity along the path segments exterior to the array. Adequate fits to the data have been obtained with isotropic velocity structures, but the differential dispersion between the SH-dominated (Love) and PSV-dominated (Rayleigh) waves requires a relatively thin lid with very high shear velocities $(\sim 5.0 \mathrm{~km} / \mathrm{s})$ and low compressional velocities $(\sim 7.8 \mathrm{~km} / \mathrm{s})$ overlying a region of low shear velocity $(<4.3 \mathrm{~km} / \mathrm{s})$. More successful fits and more plausible models are obtained by allowing for radial anisotropy in the upper mantle.

The preferred structure, designated MIT-SA3, has a crustal thickness of $41 \mathrm{~km}$, a radially anisotropic layer extending to $220 \mathrm{~km}$, and no low-velocity zone in the isotropic shear velocities. In the anisotropic layer, the SH velocities average to be about $4 \%$ greater than the SV velocities, which is slightly larger than the $3 \%$ anisotropy determined by Gaherty and Jordan (1995) for western Australia. As in the case of Australia, a sharp transition from an anisotropic to an isotropic structure introduces an L discontinuity, but the depth and sharpness of this transition are not well resolved by the preliminary data set. These results indicate that stong radial anisotropy is a feature of the Kaapvaal upper mantle, and that the well-developed shear-wave low-velocity zone obtained for southern Africa from a previous study by Qiu et al. (1996) may be an artifact caused by ignoring anisotropic effects. The existence of this anisotropy, combined with the observations by the Carnegie group of very little vertical shear-wave splitting, suggests that the orientation of anisotropy in the Kaapvaal upper mantle is heterogeneous with a vertical correlation length that is significantly smaller than its horizontal correlation length. 


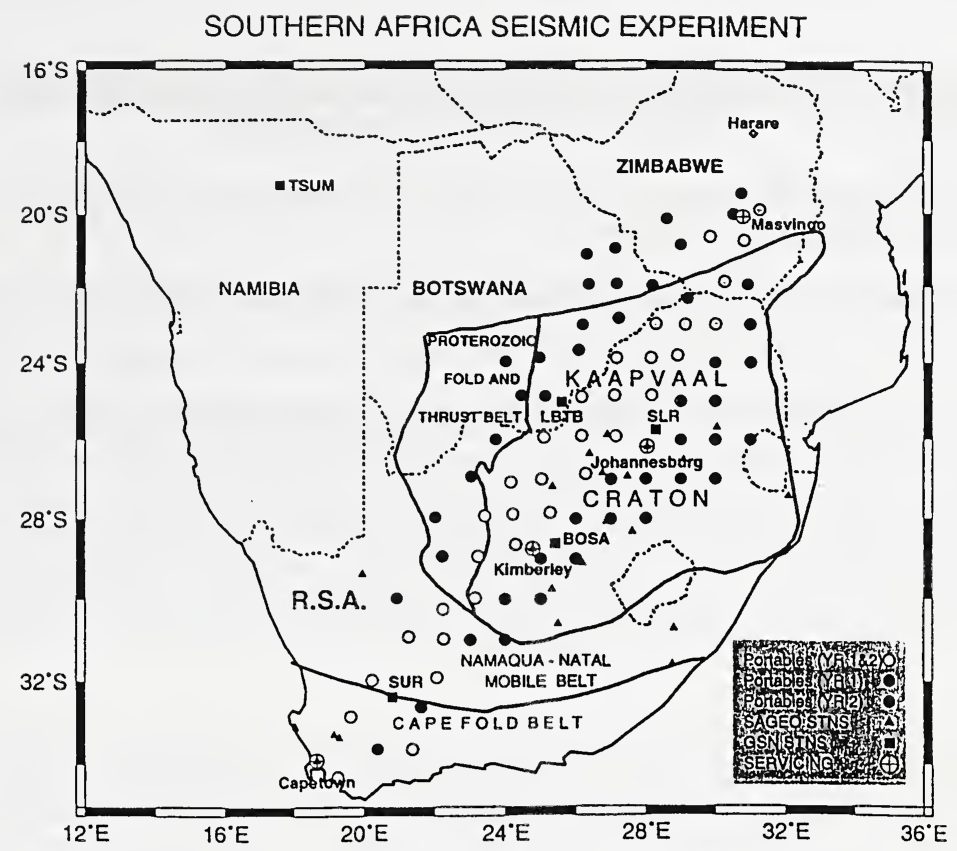

Figure 1. Map of southern Africa showing schematic outlines of the Kaapvaal craton and the adjacent Proterozoic provinces. Locations of broadband stations are shown as open and filled circles, permanent Global Seismic Network stations as solid squares, and short period stations of the South African network as solid triangles.

\section{References}

Gaherty, J. B., and T. H. Jordan, Lehmann discontinuity as the base of an anisotropic layer beneath continents, Science, 268, 1468-1471, 1995.

Grand, S., 1987, Tomographic inversion for shear velocity beneath the North American plate, J. Geophys. Res., 92, 14065-14090.

James, D. E., 1989, Continental Lithosphere, in Encyclopedia of Solid Earth Geophysics, D. E. James, editor, pp. 92-97, Van Nostrand Reinhold Co., Inc., N.Y.

James, D. E., S. van der Lee, S. Gao, P. Silver, and J. VanDecar, 1997, Kaapvaal Project: Preliminary seismic observations and analysis, supplement to Eos, Trans. Am. Geophys. Union, 78, no. 46, F495.

Jordan, T. H., 1978, Composition and development of the continental tectosphere, Nature, 274, 544-548.

Jordan, T. H., 1979, Mineralogies, densities and seismic velocities of garnet lherzolites and their geophysical implications, (in) The Mantle Sample: Inclusions in Kimberlites and Other Volcanics (F.R. Boyd and H.O.A. Meyer, eds), Am. Geophys. Union, 1-14.

Jordan, T. H., 1981, Continents as a chemical boundary layer, Phil. Trans. R. Soc. Lond. A, 301, 359-373.

Jordan, T. H., J. B. Gaherty, and R. L. Saltzer, 1997, Kaapvaal Project: Inversions of preliminary data sets for the radial anisotropic structure of southern Africa, supplement to Eos, Trans. Am. Geophys. Union, 78, no. 46, F487.

Qiu, X., K. Priestley, and D. McKenzie, The lithospheric velocity sytructure of southern Africa from regional waveform modeling, Geophys. J. Int., 127, 563-587, 1996. 
Silver, P. G., and Chan, W. W., 1988, Implications for continental structure and evolution from seismic anisotropy, Nature, 335, 34-39.

Sipkin, S. A., and T. H. Jordan, 1980, Multiple ScS travel times in the Western Pacific: implications for mantle heterogeneity, J. Geophys. Res., 85, 853-861.

Van der Lee, S. and G. Nolet, 1997, Upper mantle S-velocity structure of North J. Geophys. Res., 102, 22,81522,838 .

Zielhuis, A., and G. Nolet, 1994, Shear-wave velocity variations in the upper beneath central Europe, Geophys. J. Int., 695--715. 